\title{
A ESTRANHA INSTITUIÇÃO DA LITERATURA NO MULTIVERSO DOS ESPECTROS
}

\author{
THE UNCANNY INSTITUTION OF LITERATURE IN SPECTERS' MULTIVERSE
}

\section{Moysés Pinto Neto}

Universidade Luterana do Brasil

Porto Alegre, Brasil

\section{Resumo}

O texto busca delinear os contornos gerais da espectrologia (hantologie) a partir das ideias de "economia geral" (Bataille) e da repercussão da psicanálise freudiana enquanto modelo do real inconsistente para Jacques Derrida. Sustenta, portanto, que o domínio dos fantasmas náo pertence à ordem da representação, mas ao real enquanto tal com seus próprios direitos. Finalmente, aproxima a literatura do domínio dos fantasmas, apresentando a ficção como uma intervenção que cria o impossível.

Palavras-chave: espectrologia; Derrida; economia; psicanálise; literatura.

\section{Abstract}

The text presents general aspects of hauntology (hantologie) with the ideas of "general economy" (Bataille) and the freudian psychoanalysis' repercussion as a model for real inconsistency to Jacques Derrida. It sustains, therefore, that the ghosts' domain do not belongs to the order of representation, but to the real as itself with its own rights. Finally, it approaches literature to the domain of ghosts, presenting fiction as an intervention that creates the impossible.

Keywords: hauntology; Derrida; economy; psychoanalysis; literature.

\section{Resumen}

El texto busca delinear los contornos generales de la espectrología (hantologie) a partir de las ideas de "economía general" y de la repercusión del psicoanálisis freudiana como modelo del real inconsistente para Jacques Derrida. Así, sostiene que el dominio de los fantasmas no pertenece al orden de representación, pero al real en cuanto tal con sus propios derechos. Por fin, acerca la literatura del dominio de los fantasmas al presentar la ficción como una intervención que crea el imposible.

Palabras clave: espectrologia; Derrida; economía; psicoanálisis; literatura.

Você sabe ao menos do que eu falo, e vire-se como puder, quero dizer com esta economia, de Sócrates a Freud e além, até nós (compreendidos e incompreendidos).

(DERRIDA, Jacques. O cartão-postal.)

É possível pensar o movimento que percorre a tessitura dos fios do pensamento de Jacques Derrida de modo positivo? O filósofo não cansou de afirmar que a desconstrução era um gesto afirmativo, um duplo sim. A questáo 
da posição afirmativa não pode deixar de ser relacionada com a própria transição, muita típica da filosofia francesa dos anos 60 e inspirada em Friedrich Nietzsche, de libertar a diferença da posição dialética de negatividade. ${ }^{1}$ Já Bataille havia pensado uma negatividade irrecuperável pelo sistema dialético, ainda que distinta daquela que Adorno, de modo mais ou menos parecido, havia oposto ao sistema hegeliano. Se, para Adorno, a diferença é a transcendência, explodindo a identidade em não-identidade, para Bataille trata-se de um ponto furtivo, uma linha de fuga na própria imanência que se despende sem reserva, sem ser recuperável (DERRIDA, 2004b: 115). Cota de excesso, a negatividade sem emprego de Bataille é clara herdeira da economia da dádiva de Marcel Mauss, que influenciou de modo profundo e como em nenhum outro lugar o pensamento francês, abrindo-o para a superaçáo do etnocentrismo logocêntrico. O pensamento de Derrida, herdeiro de Nietzsche, Mauss e Bataille, faz a diferença se libertar do negativo, situando-se como condição de possibilidade da própria identidade. A diferença, nesse campo no qual o excesso não é efeito da desordem, porque não há bordas para medida, exorbita qualquer padrão. Espaço do que Bataille, tentando abrir a economia política para dimensóes anti-humanistas, nomeava economia geral (BATAILLE, 1975).

O movimento denominado desconstrução deve a Bataille, portanto, o deslocamento de uma economia restrita para a economia geral, isto é, uma economia liberada da repressão logocêntrica típica do pensamento ocidental (DERRIDA, 2004b: 400-401). Essa economia geral é verdadeiramente aneconômica, o que significa dizer anterior a toda estabilidade ou organização, à ideia de presença enquanto consistência de um objeto que se materializa em um ente portador de identidade, ou ainda mesmo do Ser, à medida que o antecede numa complicada passagem para um nível ainda anterior à polaridade ser-ente, dyferença ${ }^{2}$ (différance) mais antiga que a própria diferença ontológica de Heidegger. A economia geral, lugar dos indecidíveis e

\footnotetext{
${ }^{1}$ Para um questionamento interessante desse ponto, ver: NOYS, Benjamin. The persistence of the negative. A critique of contemporary continental theory. Edinburgh: Edinburgh University Press, 2010. Para ver como Derrida equaciona sua relação com Mauss, ver: DERRIDA, Jacques. Donner le temps: la fausse monnaie. Paris: Galilée, 1991.

${ }^{2}$ A história da tradução de différance para o português é longa (analisada e resumida por OTTONI, Paulo. "A tradução da différance: dupla tradução e double bind", Alfa, Sáo Paulo, n. 44, 2000: 45-58). Apesar de todas as variaçôes possíveis, adotei a tradução dyferença, utilizada por Rodrigo Oliveira e Jair Tadeu Fonseca, realizando uma operação antropofágica que "glauberiza" Derrida (OLIVEIRA, Rodrigo Lopes de Barros. Derrida com Makumba: o dom, o tabaco e a magia negra. Dissertação de Mestrado defendida no PPG em Letras da UFSC. Florianópolis, 2008; FONSECA, Jair Tadeu. A crítica de Glauber Rocha: escrita artística. In: ANTELO, Raul; CAMARGO, Maria Lucia de Barros. (Org.). Pós-critica. Florianópolis: Letras Contemporâneas, 2007). Além disso, ela pode se tornar operativa em várias expressóes (pode-se usar o y glauberiano para ynexistente, dyferencial, anymal, entre outros) (ver ainda PINTO NETO, Moysés. A escritura da natureza: Derrida e o materialismo experimental. Tese de Doutorado defendida no PPG Filosofia da PUCRS. Porto Alegre, 2013).
} 
de uma dyferença condição de qualquer presença, é aneconômica porque não respeita limites nem bordas. Escapar da repressão logocêntrica significa tentar abrir uma fresta, um ponto de fuga, a partir do qual a clausura que marca o dentro e fora retoma seu momento mais inconsistente, isto é, mais aberto. A gramatologia precisa funcionar no registro dessa economia geral, entendida como uma escritura sem telos ou arkhê, entregue ao puro jogo do aleatório (DERRIDA, 2004b: 423).

A formalização desse movimento é dada sobretudo na conferência $L a$ différance ( $A$ dyferença), na qual Derrida explicita alguns antecedentes filosóficos e procura delimitar a estrutura da mencionada dyferença. Assim, a ideia de dyferença concentraria em um feixe as diferentes direçóes que a sua obra tomara, descrevendo-as enquanto "sistema geral dessa economia" e, ao mesmo tempo, trazendo a ideia de uma tessitura entre diversas linhas de força (ou de sentido). Trata-se, portanto, de uma filosofia de fluxos, ${ }^{3}$ sem a rigidez do estruturalismo da época, que vai se escrevendo a partir da intricação de diversos cruzamentos. Uma filosofia que brota das margens, náo de centros organizadores. O problema está na questáo de pensar como a diferença pode exceder a identidade de modo que a própria identidade seja um caso da diferença, isto é, que a instabilidade se oponha ao conceito filosófico de arkhê, desconstruindo a própria ideia de origem de modo rigoroso. Hegel, Nietzsche, Heidegger, Saussure, Levinas e Freud são citados como pensadores que tentaram realizar esse movimento de prioridade da diferença em relação à tradição metafísica cuja marca fundamental é justamente considerar o diferencial como acidental, ou seja, como espécie de forma incompleta ou inferior de uma origem plena, presente e eterna (DERRIDA, 1972). A dyferença também pode ser tida como introdução radical da dimensão da temporalidade na configuração da forma, o que significa dizer que nada está plenamente presente, isto é, fora do tempo (geralmente se associa a presença à ausência, esquecendo-se do sentido temporal da ideia de presente como espelho da eternidade). À medida que essa dyferença anterior à distinção entre identidade e diferença precede o próprio Ser - já ele efeito desse turbilhão originário -, a própria ideia de origem implode, pois a dyferença, pensada rigorosamente enquanto tal, não é, simplesmente. Se fosse, já seria algo, e, portanto, não seria mais a pura virtualidade enquanto possibilidade pré-originária de algo ser, inclusive do próprio Ser pensado em separado dos entes. Se isso simplesmente não poderia ter sido realizado sem o espaço aberto por

\footnotetext{
${ }^{3}$ A semelhança com Gilles Deleuze é nítida, diferindo apenas nas fontes (Deleuze, por exemplo, prefere Tarde e Simondon para demonstrar a prioridade da diferença). Entre eles, de modo explícito, apenas Nietzsche. E, de fato, o Nietzsche mencionado no texto é precisamente aquele de Nietzsche et la philosophie, do fluxo de forças que jamais se faz plenamente presente (DERRIDA, 1972: 18), e não outros dos múltiplos Nietzsches recebidos pela filosofia posterior (ex.: Heidegger, Adorno, Bataille, etc.).
} 
Heidegger, é preciso ir ainda mais longe na afirmação da finitude, abrindo mão inclusive do "sentido do ser" (DERRIDA, 2004b: 37-38). É o que afirma Derrida em Ousia e Grammé, finalizando o texto após passar por Heidegger:

Semelhante dyferença dar-nos-ia já, ainda, a pensar uma escrita sem presença e sem ausência, sem história, sem causa, sem arquia, sem telos, perturbando absolutamente toda a dialética, toda a teologia, toda a teleologia, toda a ontologia. Uma escrita que excede tudo o que a história da metafísica compreendeu sob a forma da grammé aristotélica, no seu ponto, na sua linha, no seu círculo, no seu tempo e no seu espaço ${ }^{4}$ (DERRIDA, 1991a: 105, tradução modificada. No original: DERRIDA, 1972: 78).

À medida que essa dyferença não encontra limites nem bordas, uma vez que as bordas e limites são seus efeitos, ela permite pensar uma metafísica sem hierarquias ou essências, rompendo com a onto-teologia da tradição do Livro. Trata-se de uma imanência sem bordas, imanência sem totalidade ou, na linguagem de Glas e Timpanizar, imanência invaginada. Ela é por isso aneconômica, à medida que a economia envolve uma contenção desse movimento para se estabilizar em uma forma qualquer. Pensar o que poderia ser uma "ontologia", agora sem o privilégio do ser, requer se lançar nessa economia geral dos indecidíveis sem possibilidade de recorrer a um "fora-do-texto", isto é, a qualquer transcendência. Por outro lado, isso significa que é impossível simplesmente viver na absoluta dyferença: para viver, é necessário que ela seja de alguma maneira contida, por isso tudo que existe, para Derrida, é resultado de uma violência originária, o que significa também dizer uma efração, um sulcamento (frayage) capaz de deter esse movimento ilimitado de maneira econômica, sem que possa, contudo, extirpá-lo por completo na medida em que retira suas próprias forças do movimento diferencial. Não existe vida sem essa violência originária. Simultaneamente, entre outras consequências desse movimento no real, está a incontrolabilidade do sentido, questão que ganhou uma proporção provavelmente maior que a merecida devido à recepção "linguística" da obra de Derrida. Como ninguém pode ser soberano em relação ao sentido, uma vez que a disseminação é condição da estabilidade, toda obtenção de sentido se dá de modo provisório e precário, numa economia determinada.

\footnotetext{
${ }^{4}$ Na primeira versão de De la grammatologie, I, publicada na Critique, em dezembro de 1966, a posiçẫo de Derrida é ligeiramente mais clara. Lá, Derrida diz que "ser e ente, ôntico e ontológico, ôntico -ontológico" devem ser pensados "de uma só vez", ou seja, ele rejeita o dualismo heideggeriano como último refúgio da metafísica enquanto ontologia, isto é, teoria do ser (apud BARING, 2011: 190). $\mathrm{Na}$ versão posterior, Derrida modifica a redação. A leitura de Baring dessa enigmática passagem é perfeita: "He constructed the concept of différance by first determining it following Heidegger and then erasing the determination" (BARING, 2011: 191), isto é, passar pela questáo do Ser quer dizer atravessá-la e cortar o dualismo, fazendo-se uma filosofia da imanência diferencial. Nas páginas seguintes, contudo, Baring segue uma leitura diferente. Ver, por exemplo: DERRIDA, Jacques. "Entretien". In: JANICAUD, Dominique. Heidegger en France. v. 2. Paris: Aubin Michel, 2001: 89-126.
} 
Poucos anos mais tarde, após a publicação de Da gramatologia, em 1967, Derrida começa a chamar de grafemática a gramatologia, substituindo a ideia do gramma - e mesmo do rastro às vezes - pelo grafema. Essa mudança, pouco comentada pela literatura, tem um sentido de liberaçáo do logos, uma vez que o projeto gramatológico rui por essência. A gramatologia como ciência positiva nos termos logocêntricos seria uma contradição em termos (DERRIDA, 1967: 142). O grafema, como o rastro, não é necessariamente humano e nem é mero traço em um texto escrito em um papel, sendo antes um sulcamento do real enquanto escritura. A grafemática, assim, poderia ser o nome que a ontologia ganharia após estar liberada do sentido do ser, enquanto jogo contingente da escritura que não tem e, por isso, não pode ser comandada por algo fora-de-si ("não há o fora-do-texto"). Instabilidade sem fora que somente se permite ser determinada de forma econômica, sem transcendental soberano, sem essência, sem que se possa conter integralmente as forças que permitem justamente a essa economia acontecer. É essa economia geral, essa (an)economia, que irá ser identificada, para além da escritura, com a hantologie (fantasmologia ou espectrologia) - a partir de um novo feixe que entrelaça os conceitos nesse campo aberto e imanente.

Espectros de Marxé a obra em que Derrida utiliza de forma mais frequente e intensa a expressão hantologie (espectrologia), justamente opondo ontologia à espectrologia. ${ }^{5}$ A ontologia, ao afirmar o primado do ser e o dualismo ôntico/ontológico, seria mais um capítulo da metafísica enquanto clausura. Seria preciso ir além da ontologia, pensando uma dyferença que nunca se faz inteiramente presente, pois se dá em forma de rastro ou grafema, para então pensar essa escritura como uma abertura sem compromisso com qualquer transcendência que possa lhe comandar "de cima" ou "de fora". Gradualmente,

\footnotetext{
${ }^{5}$ A traduçáo brasileira, seguindo a traduçáo literal do termo hanter, traduziu a expressão por "obsidiologia", perdendo com isso seu sentido essencial, embora Derrida tenha jogado com a questão da obsessão e assombração (hanterl hantél hantise) em Marx no texto (DERRIDA, 1994: 59; DERRIDA, 1993: 89). Apesar do contraste entre espectro e fantasma, tomo-os como sinônimos, contrastando com os espíritos. Inicialmente cogitei traduzir o termo hantologie por "fantasmologia", mas acabei optando, somando os esforços aos excelentes trabalhos de Fabian Ludueña Romandini, por "espectrologia”. O sentido de espectrologia é distinto de Ludueña aqui em dois sentidos: primeiro, porque a distinção entre espírito e espectro é fundamental (em Ludueña são tomados deliberadamente como sinônimos para referir um corpo que sobrevive à morte); segundo, porque não se trata aqui de uma "ontologia política", à medida que tentarei provar que a economia geral abre a possibilidade de qualquer política, inclusive o mal radical. Dessa forma, não se trata de desconectar política e ontologia, mas de não ver nelas uma relação de transitividade direta (em Derrida, como veremos, esse seria o espaço da decisão em relação aos espectros da justiça, do dom etc.). Ver: ROMANDINI, Fabián Ludueña. La comunidad de los espectros. v. 1. Antropotecnia. Buenos Aires: Mino Dávila, 2010: 11-14. A perspectiva da dissolução do humano e da própria vida mais tarde exposta em Para além do princípio antrópico (Desterro: Cultura e Barbárie, 2012: 58-59) está mais próxima desse projeto; ainda, PINTO NETO, Moysés. A escritura da natureza: Derrida e o materialismo experimental. Tese de Doutorado defendida no PPG Filosofia da PUCRS. Porto Alegre, 2013.
} 
no entanto, a grafemática vai perdendo o destaque para uma dimensão ainda mais dessubstancializada do grafema, um momento de ainda maior inconsistência ontológica. A imagem predominante é então o "espectro". Nunca estando desatento e nem denegando os avanços científicos e tecnológicos que o mundo produzia, possivelmente o próprio avanço da cibernética na direção da informática, "virtualizando" ainda mais a dimensão escrita, levou-o a colocar em primeiro plano essa "ciência dos espectros" deixando a grafemática em segundo. Inscrição fantasmagórica cujos habitats mais nítidos são psicanálise e cinema. No livro e posteriores debates, fica claro como Derrida apenas "tolera" a expressão "ontologia", preferindo referir-se aos fenômenos por ele tratados sob uma nomenclatura transcriada. Na resposta a Negri, por exemplo, ele afirma: "I agree, agree about everything with the exception of one word: 'ontology" (DERRIDA, 2008: 257). Marx ainda estaria preso a uma ontologia, isto é, na filosofia do Ser como presença, e seria precisamente esse elemento que iria o levar à exorcização dos fantasmas. A ontologia, assim, seria uma teoria do ser enquanto ser que carrega consigo a ideia de presença, buscando, mediante uma arkhê ou um telos (como nostalgia da origem ou parousia), a plenificação de algo em si próprio, a expulsão da indeterminaçãao que nunca permite a determinação integral. Por isso, os próprios termos "real" e "material", usados abundantemente nesse texto, já seriam problemáticos, à medida que refeririam ao que existe numa forma consistente, e exatamente por isso derivada enquanto rastro da dyferença anterior. A ida ao "material" que Marx desenvolve envolveria o processo de expulsão de todo "fantasma" (isto é, de todo real na sua forma idealizada) para restituir a presença originária, maciça, aquilo que em Marx se mostra por isso como vontade de totalização, como restituiçẫo do "real como tal" sem qualquer tipo de "ilusão" que possa o afastar. Nas palavras límpidas de Derrida, "the unrestrained, classical, traditional (dare I add 'Platonic'?) desire to conjure away any and all spectrality so as to recover the full, concrete reality of the process of genesis hidden behind the specter's mask" (DERRIDA, 2008: 261). O materialismo de Marx seria, por isso, uma imagem inversa do idealismo, sem que os eixos sejam deformados, antes sendo mantidos em sua estrita posição apenas invertendo os polos. Materialismo e idealismo, como já advertia Da gramatologia, como filosofias da presença. A fantasmologia, ao contrário, seria a ciência dos espectros, do real em sua forma inconsistente, da virtualidade como condição de toda atualização. E isso não deve ser lido apenas em sentido cronológico: o virtual não é apenas algo que se mostra em cada vestígio que deixa no real, mas ele próprio faz o real tremer e se disseminar. $\mathrm{O}$ real, como a mão heideggeriana ou materialista, treme. Por isso, Derrida prefere falar de espectrologia que de ontologia, materialismo ou metafísica. 
A chave para compreensão da espectrologia é a psicanálise, anunciada desde os primeiros escritos como aquela ciência que tinha mais condiçôes de produzir conceitos fora do esquadro logocêntrico. Psicanálise como matriz teórica da espectrologia. $\mathrm{O}$ fato de ela ter se apresentado em um texto sobre Marx não é uma mera casualidade. Precisamente aqui podemos observar o vínculo entre o materialismo e a fantasmologia: é desde um debate com Marx - e portanto com o materialismo - que Derrida articula de maneira, digamos assim, "mais formal" a ideia de espectrologia. Repito que a principal objeção de Derrida ao materialismo era sua vinculação à metafísica da presença, à medida que de alguma forma o conceito de matéria estaria ligado à solidez (e portanto à substância), sem falar das pretensóes logocêntricas que percorrem as epistemologias marxistas. A espectrologia permite pensar um materialismo imaterial, isto é, que não se confunda com uma ontologia da substância. ${ }^{6}$ Vejamos como se articula esse triângulo entre materialismo, psicanálise e espectrologia.

A relação entre Derrida e a psicanálise foi das mais intensas possíveis. Autor de diversas obras sobre o tema, dificilmente Derrida pode ser ultrapassado como dos filósofos que mais tomou a sério, recebeu e aprofundou o choque que a psicanálise provocou na cultura como um todo e muito especialmente na filosofia. Entre as principais obras (textos e livros) onde Derrida toca explicitamente esse diálogo estão Freud e a cena da escritura, O cartão-postal, Psyché (vários textos), Resistências da psicanálise, Para além da crueldade e Mal de arquivo. É possível, a partir da evolução das obras, que gradualmente o problema da gramatologia e da escritura vai passando cada vez mais à psicanálise e ao fantasma. Assim, contrariando a posiçẫo daqueles que afirmam ser a filosofia de Derrida um todo único (o que, por sinal, seria paradoxal e talvez até autocontraditório), é possível verificar uma série de fraturas ao longo dos seus escritos, tal como esse deslocamento que lentamente vai se operando em direção à psicanálise e apesar de já ter sido, de certa forma, anunciado desde os primeiros escritos. Sem cair na facilidade de afirmar uma ethical turn, como se o "primeiro Derrida" tivesse sido um pensador mais voltado ao texto e somente o "segundo Derrida" às questóes práticas (o que é um completo mal-entendido sobre as primeiras obras), procura-se ler a obra como o próprio Derrida costumava ler, ou seja, vendo os segmentos, as fraturas, as continuidades, as rupturas e as feridas. Trata-se de ler plasticamente a obra de Derrida, observando os movimentos de transformação - isto é, mutação da forma - que percorrem os diversos textos do início ao fim da sua vida intelectual (MALABOU, 2005: 97-106).

\footnotetext{
${ }^{6}$ Elisabeth Roudinesco (2006) insiste em diversos textos, e inclusive do diálogo De que amanhä..., que Espectros de Marx pode ser considerado, com a mesma intensidade, um debate com Freud.
} 
De fato, desde o início a identificação de Derrida com Freud é profunda. Já em $A$ escritura e a diferença, em que realiza uma espécie de intervenção no cenário filosófico, expondo sua posição no contexto histórico-intelectual que vivenciava, Derrida dedica um texto seminal a Freud, Freud e a cena da escritura, no qual realiza a incursão em torno de alguns textos freudianos, cuja importância havia sido deixada de lado pelos próprios psicanalistas da época. Nele, o filósofo procura marcar diversos pontos de ligação com Freud, embora igualmente busque fazer o discurso freudiano avançar para além da clausura metafísica, liberando a dimensão da escritura que já ali estava contida. Entre as proposiçóes enigmáticas que abrem o texto, Derrida arrola simultaneamente uma desvinculação entre desconstrução e psicanálise, parecendo recusar a associação e, ao mesmo tempo, "elevação" da psicanálise para além da psicologia. Na primeira proposição, ele afirma:

Apesar das aparência, a desconstrução do logocentrismo não é uma psicanálise da filosofia.

Essas aparências: análise de um recalque e de uma repressão histórica da escritura, desde Platão. Este recalque constitui a origem da filosofia como episteme; da verdade como unidade do logos e da phone (DERRIDA, 2010:289. No original: DERRIDA, 2004b: 293).

Esse exercício de "psicanálise da filosofia” - que hoje pode ser ampliado até uma psicanálise da cultura - não seria totalmente novo, na medida em que Adorno e Horkheimer, na Dialética do esclarecimento, já haviam executado intento parecido, e talvez isso não tenha escapado a Walter Benjamin no seu olhar microscópico e no problema da memória que perpassa, por exemplo, as Teses sobre a história. O próprio Gaston Bachelard, por uma via totalmente diferente, já havia se aproximado da psicanálise em um sentido razoavelmente parecido, fazendo do inconsciente um estágio primordial para se alcançar a consciência científica numa construçấo da epistemologia a partir das imagens inconscientes primárias que iriam aos poucos se refinando com rupturas e superação de obstáculos. No entanto, conquanto o recalque seja uma estrutura sem a qual a desconstrução não teria operado, não é esse o enfoque que Derrida faz operar na psicanálise, pois ele seria ainda parte da história da metafísica, da "época da presença, em seu sentido heideggeriano, e a sua nervura central, de Descartes a Hegel: a presença como consciência, a presença para si pensada como oposição consciente / inconsciente” (DERRIDA, 2004a: 291), à medida que faria do inconsciente uma estrutura secundária que deveria ser absorvida como negatividade em um logos amplificado. Em outros termos: o trabalho em relação ao recalque que "traz à consciência” o recalcado é, na visão de Derrida, ainda uma espécie de pertencimento da psicanálise à metafísica. Se a desconstrução é propriamente a abertura da clausura metafísica, ela não 
pode reafirmar o primado da consciência, fazendo do inconsciente, mais uma vez, acidente subordinado. Os fios aqui se ligam e desligam de forma mais complexa e dividida, os polos se deformam em novas configuraçóes, requerendo propriamente toda uma reconstruçáo conceitual para não cair novamente, apesar da intenção inovadora, nas velhas malhas do logocentrismo.

Em Da gramatologia, por outro lado, Derrida parece afirmar exatamente o inverso em relação à psicanálise. Se a desconstrução não é uma "psicanálise da filosofia", como pode, ao mesmo tempo, afirmar Derrida que de todas as ciências regionais aquela que tem mais chance de prosperar fora da clausura é a psicanálise? Ou, mais agudamente ainda, quando afirma seguidas vezes, repetindo isso até o fim de sua vida, que a psicanálise não é simplesmente uma ciência regional e que o choque que ela causou ainda não teria sido absorvido pelas mais diversas áreas? Os limites do que chamamos psicanálise, para Derrida, exorbitam a "psicologia", ainda dominada pelo valor da consciência e pelo subjetivismo que se construiu desde Descartes. Sabe-se que Derrida, na esteira de Husserl, sempre colocou restriçóes a qualquer tipo de "psicologismo". Como conciliar esses três pontos? Derrida afirma ao mesmo tempo: (1) a desconstrução não é uma psicanálise da filosofia (DERRIDA, 2004b: 295-295); (2) a psicanálise é a mais próspera das ciências na abertura da época da clausura, não se confundindo com as ciências regionais (DERRIDA, 1967: 132); e (3) nenhum psicologismo pode resolver os problemas fundamentais da filosofia (BARING, 2011: 117). Eis, então, em resposta a estas três pontas de fios sem aparente ligação, uma das teses arriscadas que este texto defenderá: a psicanálise freudiana não é apenas um modelo do fenômeno da "psiqué" humana; ela antes apresenta a estrutura do real, isto é, um modelo que poderíamos nomear, na linguagem clássica, de ontologia. Em outros termos: aquilo que, em Derrida, serve de base positiva para seu discurso, sua "ontologia", encontra seu melhor modelo teórico em Freud. O papel que o estruturalismo deu para a linguística ou um tipo de idealismo, por exemplo, dá para a matemática (p.ex., do passado remoto ao presente: Pitágoras, Platão, Descartes, Leibniz, Badiou, Meillassoux) ou para a lógica formal (p.ex., Aristóteles, Frege, Russel, o primeiro Wittgenstein) poder-se-ia dizer - ainda que com certo risco - que Derrida dá à psicanálise. Na linguagem cartesiana, ainda hoje dominante na filosofia, a psicanálise para Derrida não é apenas "subjetiva", isto é, pertencente ao âmbito dos fenômenos psicológicos, mas "objetiva", isto é, capaz de funcionar como modelo para pensar a estrutura dos fenômenos em geral, inclusive os que estão fora da mente. Na linha das afirmaçóes que percorreram as primeiras obras, ao afirmar que a psicanálise era o campo que tinha mais condição de avançar na abertura da clausura metafísica, poder-se-ia afirmar que a semiologia está para a gramatologia como a 
linguística está para a psicanálise, formando paralelos assimétricos no deslocamento da linguagem para a escritura (semiologia-linguística-linguagem/ gramatologia-psicanálise-escritura).

Isso somente será possível graças ao conceito central que alicerça o próprio edifício psicanalítico: o inconsciente. ${ }^{7}$ Para Derrida, o inconsciente que Freud "descobre" não é apenas uma estrutura psíquica, sendo isso mero resíduo da "época cartesiana" (que pensa a presença como sujeito), mas a estrutura do real. Essa transposição pode parecer complicada, e é: trata-se de pensar a condiçấo de finitude originária afirmativamente, isto é, como dyferença, e para isso o modelo do inconsciente fornece uma fluidez capaz de escapar da clausura da tradição. Exatamente por esse motivo hoje é possível pensar em modelos alternativos para essa nova economia, por exemplo, as neurociências, a termodinâmica, a física quântica ou, inclusive, outras culturas. ${ }^{8}$ Não se trata de um argumento de autoridade invocando a psicanálise, nem tãosomente uma discussão intrapsicanalítica (embora ela exista), mas da possibilidade de utilizar seu arsenal teórico - pensado a partir de um referencial indeterminado - para ultrapassar os conceitos da tradição.

Uma vez que a psicanálise nasce pensando a inconsistência do inconsciente, torna-se modelo da economia geral de Bataille. Ou seja: a psicanálise ao apontar para a crueldade (o dispêndio) "sem álibi" - é a própria economia geral ou aneconomia em Derrida (DERRIDA, 2001b; DERRIDA, 2004a: 207208). Aquilo que Bataille buscou a partir da experiência trágica e todas as formas de dispêndio, finalizado com a ideia de "parte maldita", recebe uma nova coloração a partir da análise do inconsciente enquanto campo primeiramente

\footnotetext{
7 "Une certaine alterité - Freud lui donne le nom métaphysique d'inconscient - est définitivament soustraite à tout processus de présentation par lequel nos l'appellerions à se montrar en personne. Dans ce contexte et sous ce nom, l'inconscient n'est pas, comme on sait, une présence à soi cachée, virtuelle, potencielle. Il se différe, cela veut dire sans doute qu'il se tisse de différences et aussi qu'il envoie, qu'il delègue des représentants, des mandataires; mais il n'y a aucune chance pour que le mandant 'existe', soi présent, soi 'lui-même' quelque part et encore moins devienne conscient. En ce sens, contrairement aux termos d'un vieux débat, fort de tous les investissements métaphysiques qu'il a toujours engagés, l' 'inconsciente' n'est pas une 'chose qu'autre chose, pas plus une chose qu'une conscience virtuelle ou masquée. Cette altérité radicale par rapport à tout mode possible de présence se marque en des effects irréductibles d'après coup, de retardement. Et, pour les décrire, pour lire les traces des traces "inconscientes" (il n'y a pas de trace "consciente"), le langage de la présence ou de l'absence, le discours métaphysique de la phénomenologie est inadéquat" (DERRIDA, 1972: 21).

${ }^{8} \mathrm{O}$ próprio Derrida apresentou alguns modelos alternativos na sua obra, com o destaque decisivo para a literatura e a poesia (p. ex.: DERRIDA, 1991b: 190-191). Na Gramatologia, Mallarmé é visto como o primeiro a escapar da época logocêntrica (DERRIDA, 1967: 99-100). Além desses exemplos, podemos pensar nas novas tecnologias (começando pela menção à cibernética e chegando à informática nos escritos finais), no cinema (citado, ao lado da psicanálise, como lugar privilegiado do fantasma no filme Ghost Dance; também em DERRIDA, 2001a; e DERRIDA; STIEGLER, 2002), na genética e na etologia como modelos que Derrida menciona capazes de transbordar a conceitualidade metafísica tradicional.
} 
aneconômico, ou posto em termos de uma economia geral. Lembre-se, nesse sentido, que Freud propóe um modelo econômico do inconsciente, fundado numa matriz energética e cujo conteúdo é fantasmático, tornando-se dessa forma uma imagem ontológica bastante produtiva. Também por essa razáo, Jean-François Lyotard, como esteve tão perto de Derrida em tantas questóes, propôs um pensamento da economia libidinal na crítica ao capitalismo; e Bernard Stiegler, cujo trabalho em boa parte é legatário de Derrida, propóe precisamente uma retomada da ideia de economia libidinal de Lyotard a partir do problema do esgotamento da energia desejante na sociedade de consumo. A base fática da qual parte a psicanálise é uma economia da vida/morte, precisamente o modelo de materialismo energético com forças sem presença - palimpsesto de rastros - que Derrida desenha. A diferença entre princípio do prazer e da realidade, por exemplo, "não é apenas nem em primeiro lugar uma distinção, uma exterioridade, mas a possibilidade originária, na vida, do desvio, da dyferença (Aufschuh) e da economia da morte" (DERRIDA, 2010: 291-292. No original: DERRIDA, 2004b: 295).

Nomear a psicanálise de "ontologia", contudo, estaria em contradição com o que ela justamente proporciona: a possibilidade de se pensar a partir do inconsciente o fantasmático (inconsistente) que precede a dureza do que nomeamos, ainda bastante habituados à ontologia da substância e da presença, "real". A dissolução desse real em sua forma espectral - na linguagem de Derrida, na dyferença que antecede suas formas estáveis - é propriamente o legado que a psicanálise deixa para que se escape do domínio da presença na filosofia, tanto em suas versōes idealistas quanto nas materialistas. Esse choque é uma ruptura tão significativa - ou simplesmente desconstrutiva - da tradição que o próprio Freud, como Derrida demonstra diversas vezes, recua diante dele, recalcando os fantasmas enquanto tais. Exatamente no momento em que Freud está mais distante da tradição filosófica, o scholar cientista deve reaparecer, domesticando os conceitos para se adequarem à epistemologia tradicional, fazendo do inconsciente um fenômeno restrito ao âmbito psicológico. Freud nega a existência do próprio espaço espectral que ele revelou. Por isso, a tradição, como diz a epígrafe deste texto, "de Sócrates a Freud, e além”. Freud está para Derrida como Nietzsche está para Heidegger: na fronteira entre o além-da-metafísica e como seu último suspiro, sua forma-limite (DERRIDA, 2001c: 110; 2004a: 294).

A intimidade da psicanálise com os fantasmas nasce da decisão metodológica de Sigmund Freud, que a funda enquanto domínio próprio quando reconhece a fantasia como elemento com seu estatuto próprio de realidade psíquica; Freud abre espaço para que os espectros ingressem livremente no campo da ciência. Como já dito, Derrida anota várias vezes que o próprio 
Freud não resistiu a esses espectros, denegando frequentemente a existência de fantasmas reais (DERRIDA, 2001c: 118-122). No entanto, a porta que abriu para o virtual desestabiliza de forma definitiva a oposição platônica, já bastante tumultuada por Nietzsche, entre o real enquanto verdade e a ficção como irrealidade. O domínio do sonho, sua "maior descoberta", descortina um território eminentemente fantasmagórico da realidade. O sentido do sonho que excede a lógica do epifenômeno desestabiliza mais uma vez a oposição entre ficção e realidade, mostrando a realidade da ficção.

O que a psicanálise apresenta como fenômeno psíquico, no entanto e como já afirmado, pode ser o paradigma também da realidade mesma. Não se trata apenas de um campo simbólico que se aproxima da loucura, como Žižek postula (ŽIŽEK, 2013: 156-165), mas da loucura imanente ao próprio real enquanto tal. O que o inconsciente revela em sua inconsistência espectral é que o próprio real não se submete a uma ordem eterna e transcendente, sendo antes efeito do turbilhão dyferencial enquanto economia determinada. Quando Markus Gabriel afirma que "o mundo não existe", apresentando-se apenas mediante transfinitos campos de sentido, não se trata de uma afirmação sobre a representaçâa da realidade, mas sim sobre sua inconsistência enquanto real (GABRIEL, 2009; 2011). Do ponto de vista da economia geral, o real é apenas um sonho que endureceu.

A literatura habita o mesmo espaço espectral que o sonho. A ficção é aquilo que não cansa de lembrar as infinitas variaçóes do possível. Não por acaso Derrida vinculava a "estranha instituição da literatura", lembrando do papel do estranho na psicanálise e que nenhuma palavra é casual para esse filósofo, ao papel de condição da democracia (DERRIDA, 2004a: 152-156). Se esta é a própria khora do político, superfície plástica na qual ele se inscreve infinitamente, a literatura é o permanente exercício do impossível enquanto lugar onde "tudo se pode dizer". Chama-se ficção justamente esse impossível que acontece, arrombando o campo pré-dado de qualquer programaçáo. A monstruosidade da literatura é da ordem do espectral, real com seus próprios direitos, sem configurar uma representação. Habitando o limiar entre o vivo e o não vivo, literatura é a intervenção que assombra o instituído, um espectro que ronda a naturalizaçáo do hábito enquanto a sombra do impossível.

Como o sonho, a literatura acontece com o sono da razão, quando os monstros acordam.

\section{Referências bibliográficas}

BARING, Edward. The Young Derrida and French Philosophy, 1945-1968. New York: Cambridge University Press, 2011. 
BATAILLE, George. A parte maldita. Trad. J. Guimarães. Rio de Janeiro: Imago, 1975.

DERRIDA, Jacques. A escritura e a diferença. Trad. Maria B. M. Nizza da Silva et al.

4. ed. São Paulo: Perspectiva, 2010.

. "Marx and his sons". In: SPRINKER, Michael (Ed.). Ghostly Demarcations.

London/New York: Verso, 2008.

. Da gramatologia. Trad. Miriam Chnaiderman e Renato Janine Ribeiro. São

Paulo: Perspectiva, 2004a.

. L'Écriture et la différence. Paris: Seuil, 2004b.

. "El cine y sus fantasmas". Trad. Fernando La Valle. Cahiers du cinéma, n.

556, abr. 2001a. Entrevista concedida a Antoine de Baecque e Thierry Jousse.

. "Entretien”. In: JANICAUD, Dominique. Heidegger en France. v. 2. Paris:

Aubin Michel, 2001b.

. Mal de arquivo: uma impressão freudiana. Rio de Janeiro: Relume-Dumará, 2001c.

. Espectros de Marx. Rio de Janeiro: Relume-Dumará, 1994.

Spectres de Marx. Paris: Galilée, 1993.

. Margens da filosofia. Trad. Joaquim Costa e Antonio Magalhães. Campinas:

Papirus, 1991a.

. Donner le temps: la fausse monnaie. Paris: Galilée, 1991 b.

- Marges de la philosophie. Paris: Minuit, 1972.

De la grammatologie. Paris: Minuit, 1967.

DERRIDA, Jacques; STIEGLER, Bernard. Echographies of Television. Trad. Jennifer Bajorek. London: Polity, 2002.

GABRIEL, Markus. Transcendental Ontologies: Essays on German Idealism. London: Continuum, 2011.

GABRIEL, Markus. "The mythological being of reflection - an essay on Hegel, Schelling, and the contingency of necessity". In: GABRIEL, Markus; ŽIŽEK, Slavoj. Mythology, madness and laughter: subjectivity in German Idealism. London: Continuum, 2009.

MALABOU, Catherine. La plasticité au soir de l'écriture: dialetique, destruction, déconstruction. Paris: Léo Scheer, 2005.

ROUDINESCO, Elisabeth. "Jacques Derrida: spectres de Marx, spectres de Freud". In: BPI. Un jour Derrida: actes du colloque organisé par la Bpi. Paris: Centre Pompidou, 2006.

ŽIŽEK, Slavoj. Menos que nada: Hegel e a sombra do materialismo histórico. Trad. Rogério Bettoni. São Paulo: Boitempo, 2013.

Moysés Pinto Neto é doutor em Filosofia pela Pontifícia Universidade Católica do Rio Grande do Sul (PUCRS). Professor da Universidade Luterana do Brasil e do Centro Universitário do Vale do Taquari - RS. Email: <moysespintoneto@gmail.com> 